\title{
DAMPAK BRAND IMAGE DAN CUSTOMER EXPERIENCE TERHADAP CUSTOMER SATISFACTION (STUDI PADA PENONTON BIOSKOP XXI DI SURABAYA)
}

\author{
Yohanes Geraldi Yuda Pradipta \\ Universitas Negeri Surabaya \\ yohanespradipta@mhs.unesa.ac.id
}

\begin{abstract}
The pressures from such high activity will cause tension, fatigue, fatigue, and stress. Currently, the cinema industry has a promising market, shown by people who have high enthusiasm to watch in the cinema. The impact of brand image and consumer experience on cinema consumer satisfaction is an interesting topic to study. This research was intended to investigate and analyze the influence of brand image and customer experience with the satisfaction of cinema viewers in XXI Surabaya. The purposive sampling method was used through the judgmental sampling method for 50 samples. The hypothesis is tested through multiple linear regression analysis. The results of the first tested hypothesis were found that the brand image variable positively and significantly affected the satisfaction of XXI cinema viewers. The results of the second hypothesis test show that the customer experience variable has a positive and significant effect on customer satisfaction watching at the XXI cinema.
\end{abstract}

Keywords: brand image; cinema; consumer experience; customer satisfaction.

\section{PENDAHULUAN}

Bioskop adalah suatu perusahaan atau usaha yang bergerak dalam bidang pemutaran film untuk umum atau semua golongan masyarakat dengan pembayaran yang dilakukan pada tempat atau bangunan tertentu (Hadi, 2017). Bioskop menjadi salah satu sarana hiburan yang paling banyak dikunjungi pada saat ini. Industri bioskop Indonesia saat ini diisi oleh beberapa perusahaan, antara lain Cineplex 21 Grup dengan Bioskop "Cinema XXI"-nya dan CJ CGV dengan "CGV Cinemas". Dua perusahaan ini saling bersaing di kelas bioskop yang sama. Bioskop Cinema XXI untuk pertama kalinya didirikan di Plaza Indonesia Entertainment X'nter pada bulan Januari 2004. Cinema XXI yang pertama kali didirikan ini dilengkapi dengan fasilitas 4 ruang teater reguler dan 2 ruang teater Premiere (thejakartapost.com, 2014). Berdasarkan Filmindonesia.or.id (2017), dunia bioskop di Indonesia diisi oleh beberapa perusahaan bioskop. Perusahaan bioskop tersebut antara lain Cinema 21 yang telah berganti nama menjadi Cinema XXI, CGV, Cinemaxx, Independen, New Star Cineplex, Platinum Cineplex dan Movimax. Bioskop Cinema XXI berada di peringkat pertama dengan 165 bioskop dan 927 layar. Pada peringkat kedua diduduki oleh CGV dengan jumlah bioskop sebanyak 37 bioskop dan 247.

Berdasarkan Filmindonesia.or.id (2017), market share bioskop-bioskop di Indonesia. Data menunjukkan bahwa jumlah bioskop dan jumlah layar bioskop yang tersedia di Indonesia cukup besar, dengan Cinema XXI menduduki peringkat pertama dengan persentase jumlah bioskop 62,73\% dan jumlah layar dengan persentase $65,65 \%$ dan CGV menduduki peringkat kedua dengan persentase jumlah bioskop sebesar 14,07\% dan persentase jumlah layar sebesar 14,29\%. Jumlah tersebut tersebar di berbagai wilayah di Indonesia, khususnya kota-kota besar seperti Jakarta, Semarang, Jogjakarta, Surabaya, Malang, dan Medan.

Berdasarkan databoks.katadata.co.id (2019) terlihat bahwa jumlah penonton bioskop Indonesia tiap tahunnya mengalami peningkatan. Peningkatan paling pesat berada pada tahun 2015-2016, di mana pada tahun 2015 terdapat 16,2 juta penonton dan pada tahun 2016 terdapat 37,2 juta penonton. Sedangkan pada tahun 2018 jumlah penonton bioskop mencapai 50 juta penonton. Hal ini menunjukkan bahwa masyarakat memiliki antusiasme yang tinggi untuk menonton di bioskop. 
Dalam usahanya memenuhi kepuasan konsumen, bioskop harus mengetahui pola-pola konsumsi dan keinginan masyarakat saat ini. Dalam konsep marketing dijelaskan bahwa marketing adalah proses perusahaan dalam membentuk nilai bagi pelanggan dan membangun relasi yang kuat dengan pelanggannya, dengan maksud menangkap nilai yang didapatkan dari pelanggan sebagai balasannya (Kotler, 2008).

Cronin dan Taylor dalam Sondakh (2014) menjelaskan bahwa kepuasan pelanggan merupakan faktor paling penting dalam menentukan nilai service quality, dimana konsumen menilai kinerja layanan dari produk yang diterima dan yang dirasakan langsung. Engel et al (1994) mendefinisikan customer satisfaction sebagai penilaian purnabeli dimana alternatif yang dipilih paling tidak sama atau melampaui harapan pengguna. Dalam rangka pemenuhan kepuasan pelanggan, brand image adalah salah satu variabel yang memiliki pengaruh dalam menentukan tingkat kepuasan pelanggan. Brand Image positif dapat diketahui melalui reaksi konsumen mengenai brand association pada merek tersebut. Brand Image terdiri dari beberapa komponen yaitu asosiasi merk dan strength (kekuatan), favorability (kebermanfaatan) dan uniqueness (keunikan) dari brand association. Deng an citra merek, produk akan dapat dikenali oleh konsumen, konsumen dapat melakukan penilaian purnabeli terhadap kualitas produk atau jasa, konsumen dapat mengurangi risiko-resiko dari pembelian, dan konsumen akan memperoleh pengalaman tertentu serta mendapatkan kepuasan tertentu dari suatu produk.

Dalam konteks fitur, fasilitas utama maupun pendukung Cinema XXI dan CGV Cinemas memiliki banyak kesamaan. Perbedaan paling terlihat adalah desain yang dipilih, di mana XXI memilih desain mewah, yang menyediakan ruang games, lounge, ruang merokok hingga kafetaria dan CGV mengusung tema desain Cultureplex. Selain desain, ada beberapa film yang tidak diputar di XXI tetapi diputar di CGV Cinemas (jatenglive.com, 2018) Berdasarkan perbedaan desain dan film yang diputar ini, penonton akan mengalami pengalaman yang berbeda ketika mengujungi kedua bioskop tersebut. Saat ini XXI Cinema menguasai pasar bioskop Indonesia sebesar 62,73\%, padahal CGV sebagai pesaing yang hanya memiliki persentase $14,07 \%$ adalah brand bioskop yang berasal dari Korea dan menawarkan Customer Experience yang berbeda dari XXI, yaitu tema European Vintage yang memberikan warna baru dalam dunia perbioskopan Indonesia dan menayangkan film-film yang ditayangkan dan tidak ditayangkan di XXI.

Tujuan penelitian ini adalah menjelaskan pengaruh brand image dan customer experience terhadap customer satisfaction penonton bioskop XXI di kota Surabaya, Jawa Timur.

\section{KAJIAN PUSTAKA DAN PENGEMBANGAN HIPOTESIS}

\section{Merek (Brand)}

Menurut Kotler dalam Tjiptono et al (2015) terdapat enam pengertian yang bisa diinterpretasikan melalui suatu brand, yaitu: Instrumen identifikasi untuk memudahkan prosedur penanganan atau pelacakan produk bagi perusahaan; Cara perlindungan hukum terhadap karakteristik produk yang bersifat eksklusif; Patokan taraf mutu bagi pengguna yang merasa puas, sehingga dapat dengan mudah memilih dan melakukan pembelian ulang produk atau jasa tersebut pada waktu yang akan datang; Medium untuk membentuk asosiasi dan makna khas yang membedakan produk atau jasa dari para kompetitor; sumber keunggulan dalam persaingan, terutama melalui perlindungan hukum, kesetiaan pelanggan, dan image khas yang terbentuk dalam pikiran konsumen; sumber finansial returns terutama dikaitkan dengan pendapatan masa depan.

Menurut Folley (2006) brand adalah kumpulan janji, asosiasi, image, dan emosi yang bersatu untuk menciptakan loyalitas konsumennya. Dengan memenuhi kumpulan diatas, maka loyalitas akan terbentuk terhadap suatu brand tertentu.

\section{Citra Merek (Brand Image)}

Brand Image (citra merek) merupakan penggambaran dari persepsi secara utuh terhadap merek, wujud dari informasi serta pengalaman masa lampau terhadap merek tersebut. Citra merek yang 
dimiliki konsumen terhadap suatu merek akan meningkat kemungkinan untuk melakukan pembelian (Sondakh, 2014). Brand image positif dapat diketahui dan dinilai melalui respon konsumen tentang asosiasi merek pada merek tersebut. Brand Image terdiri dari dua bagian yaitu brand association (asosiasi merek) dan strength, favorability dan uniqueness of brand association sebagai indikatornya (Kotler, 2013)

Dalam penelitian ini, pengukuran brand image dilakukan dengan metode free association di mana pengukuran dilakukan dengan memberikan pertanyaan kepada subjek mengenai apa yang ada di benak mereka tentang sebuah produk maupun merek (Keller, 2013). Berdasarkan hasil free association yang dilakukan, Bioskop XXI memiliki Brand Image yang positif dalam benak konsumen, beberapa persepsi yang konsumen ungkapkan antara lain, Bioskop XXI memiliki suasana nyaman, film yang diputar selalu film terbaru, memiliki kualitas sound yang baik, dan bersih.

\section{Customer Experience}

Menurut Schmitt dalam Mantala (2016), customer experience (pengalaman konsumen) didefinisikan sebagai suatu kejadian, keadaan atau kondisi yang dialami secara individu dan terjadi sebagai tanggapan dari stimulus atau perangsang tertentu, misalnya melalui berbagai strategi marketing sebelum dan sesudah penjualan. Pengalaman menjelma sebagai hasil dari mengalami dan melakukan situasi tertentu yang dipicu melalui rangsangan-rangsangan pada panca indra, perasaan dan pikiran

Menurut Schmitt dalam Mantala (2016) strategi pengukuran Customer Experience (pengalaman pelanggan) dapat diwujudkan melalui lima indikator yaitu: Sense (Indra) yang meenyangkut panca indra manusia (penglihatan, pendengaran, pengecapan, perabaan dan penciuman) yang dapat dihasilkan dengan memberikan visual yang menarik, aroma dan rasa yang menggiurkan, sentuhan yang nyaman dan musik yang sesuai. Feel (Perasaan) yang merupakan perasaan dan emosi yang memiliki sifat positif yang hadir pada saat konsumen mengkonsumsi suatu produk atau jasa. Think (Berpikir) yang memiliki definisi kapabilitas untuk berpikir secara elaboratif dan kreatif yang dimiliki oleh konsumen tentang evaluasi terhadap produk, jasa, merek maupun perusahaan. Act (Tindakan) yaitu menyangkut perubahan interaksi, dan lifestyle yang muncul, yaitu dengan membuat konsumen lebih aktif serta reaktif terhadap produk atau jasa tersebut dan yang terakhir adalah Relate (Hubungan) yaitu medium perusahaan untuk mengaitkan merek dengan individu konsumen atau budaya tertentu yang dianut.

\section{Kepuasan Pelanggan (Customer Satisfaction)}

Kotler dan Amstrong (2005) menyatakan bahwa customer satisfaction adalah kategori hierarkis di mana perceived performance produk atau jasa yang diterima akan sesuai dengan ekspektasi pelanggan. Apabila kualitas produk atau jasa yang dihasilkan lebih rendah dari harapan pelanggan, pembeli akan merasa tidak puas. Sebaliknya bila kualitas yang diperoleh konsumen sesuai dengan harapan atau melebihi harapan, pembelinya merasa puas

Menurut Durianto dalam Sondakh (2014) customer satisfaction merupakan tanda yang dipakai oleh konsumen untuk menyimpulkan suatu himpunan aksi atau tindakan yang terlihat, terpaut dengan produk atau jasa yang diterima olehnya. Dari interpretasi yang ada di atas, maka dapat disimpulkan bahwa customer satisfaction adalah perasaan yang bersifat positif disertai dengan sikap oleh konsumen setelah mereka mengalami suatu situasi atau kondisi pada saat mereka mengkonsumsi produk atau jasa tersebut. Hawkins dan Lonney dikutip dalam Tjiptono (2001) karakter pembentuk dan pengukuran kepuasan konsumen yang akan dipakai sebagai indikator terdiri dari kesesuaian harapan, di mana kesesuaian harapan menggambarkan tingkat kecocokan antara kinerja produk yang diinginkan oleh konsumen dengan yang dirasakan atau dialami oleh konsumen.

\section{Hubungan antar Variabel}

Variabel Brand Image mempunyai hubungan dengan variabel customer satisfaction. Hal ini ditunjukkan oleh penelitian Setyowati (2016) di mana variabel citra merek memberikan pengaruh positif dan signifikan bagi kepuasan pelanggan. Hal ini mempunyai arti bahwa semakin baik atau 
tinggi brand image sebuah merek maka semakin tinggi kepuasan pelanggan; dan semakin buruk atau rendah brand image sebuah merek, maka semakin rendah kepuasan pelanggan. Referensi yang mendukung pernyataan ini adalah riset yang dihasilkan oleh Prastiyani et al (2016) yang menyatakan bahwa brand mage memberikan pengaruh positif dan signifikan terhadap costumer satisfaction konsumen SPBU 44.513.20 Campurejo Boja. Penelitian dari Ehsan Malik et al., (2012) juga menunjukkan bahwa brand image memberikan dampak positif dan signifikan terhadap customer satisfaction.

H1: Ada pengaruh brand image terhadap customer satisfaction penonton bioskop XXI di Kota Surabaya.

Variabel customer experience memberikan pengaruh terhadap customer satisfaction. Hal ini ditunjukkan oleh penelitian Chandra (2014) di mana variabel ini berpengaruh terhadap customer satisfaction. Hal ini mengindikasikan bahwa semakin baik atau buruk experience yang dialami customer, semakin baik atau buruk pula customer satisfaction. Penelitian lain yang mendukung pernyataan ini adalah penelitian milik Venkat, Ramesh (2007) di mana customer experience berpengaruh kepada kepuasan pelanggan

H2: Ada pengaruh customer experience terhadap customer satisfaction penonton bioskop XXI di Kota Surabaya.

\section{METODE PENELITIAN}

Jenis penelitian ini adalah penelitian deskriptif verifikatif. Data yang digunakan dalam riset ini adalah data primer dan data sekunder. Variabel bebas yang terdapat dalam penelitian ini adalah brand image dan customer experience. Sedangkan variabel terikat dalam riset ini adalah customer satisfaction. Populasi yang menjadi sasaran adalah penonton berusia 17-35 tahun yang pernah menonton di bioskop XXI Surabaya minimal 3 kali. Jumlah sampel yang akan dipakai pada penelitian ini adalah 50 orang. Media penelitian yang digunakan adalah angket kuesioner yang didistribusikan secara online melalui angket Google Form yang disebarluaskan melalui media sosial seperti Whatsapp, Instagram, Line dan Twitter.

Teknik pengambilan sampel yang digunakan oleh peneliti adalah purposive sampling, di mana teknik yang digunakan adalah judgemental sampling dan snowball sampling yang dipilih dari responden awal kemudian dilakukan uji validitas dan reliabilitas pada instrumen penelitian yang akan digunakan. Jumlah data yang digunakan untuk uji validitas dan reliabilitas adalah 50 data responden. Setelah lolos uji tersebut, maka selanjutnya akan disebar untuk memperoleh 50 responden yang selanjutnya dilakukan uji validitas dan reliabilitas kembali untuk mengetahui jawaban responden valid dan reliabel dengan harapan dapat lolos uji asumsi klasik dan memenuhi model regresi linier berganda. Data yang terkumpul dianalisis dengan regresi linier berganda dengan memakai uji asumsi klasik yaitu uji normalitas, uji multikolinieritas dan uji heterokedastisitas. Selanjutnya, data akan diproses dengan pengujian hipotesis dengan menggunakan uji t dan uji koefisien determinasi.

\section{HASIL DAN PEMBAHASAN}

\section{Uji Validitas dan Reliabilitas}

Pada penelitian ini, masing-masing item pernyataan variabel akan dilakukan uji validitas dan reliabilitas dengan menggunakan bantuan program SPSS 25. Jumlah data yang akan diuji sebanyak 50 data responden. Setelah dilakukan uji validitas dengan menggunakan SPSS, semua item dalam penelitian ini telah memenuhi kriteria valid di mana r-hitungnya di atas 0,361. Sedangkan uji reliabilitas, variabel telah memenuhi syarat reliabel dengan hasil croanch alpha lebih besar dari 0,70. Berdasarkan hal tersebut dapat dijelaskan bahwa instrument penelitian reliabel dan dapat digunakan sebagai alat ukur penelitian 
Yohanes Geraldi Yuda Pradipta. Dampak Brand Image dan Customer Experience terhadap Customer Satisfaction (Studi Pada Penonton Bioskop XXI di Surabaya)

\section{Uji Normalitas}

Uji Normalitas dalam penelitian ini bertujuan untuk membuktikan nilai residual variabel terikat (customer satisfaction) dan variabel bebas (brand image dan customer experience) model regresi pada penelitian ini memiliki distribusi normal. Uji normalitas dalam riset ini dilakukan melalui Uji grafik normal P-plot dan Uji statistic non parametric Kolmogorov Smirnov. Hasil penjabaran uji grafik normal P-Plot menggambarkan poin-poin yang berbentuk titk-titik menyebar di sekitar garis diagonal dan mengikuti garis lurus diagonal yang menandakan data berdistribusi normal. Hasil uji statistic non parametric Kolmogorov Smirnov lebih besar dari 0,05 menunjukkan bahwa data berdistribusi normal.

\section{Uji Multikolinieritas}

Uji multikolinearitas bertujuan untuk menguji apakah model regresi ditemukan adanya korelasi antar variabel bebas (independen). Model regresi yang baik seharusnya tidak terjadi korelasi antar variabel bebas. Berdasarkan hasil uji multikolinieritas dengan metode VIF dalam penelitian ini dapat diketahui bahwa nilai tolerance brand image dan customer experience bernilai lebih dari 0,10 yang menunjukkan tidak terjadi multikolinearitas. Selanjutnya, untuk nilai VIF dari variabel brand image dan customer experience memiliki nilai VIF memiliki nilai kurang dari 10 yang menunjukkan bahwa tidak terjadi multikolinearitas.

\section{Uji Heteroskedastistas}

Uji heterokedastisitas bertujuan untuk menguji apakah dalam sebuah model regresi terjadi ketidaksamaan varians dari suatu residual satu pengamatan ke pengamatan lainnya. Penelitian ini menggunakan grafik scatterplot untuk mendeteksi hasil uji heteroskedastistas. Pada output Scatterplots di atas diketahui bahwa titik-titik data penyebar di atas dan di bawah atau di sekitar angka 0 , titik-titik tidak mengumpul (hanya di atas atau di bawah saja) dan penyebaran titik-titik data tidak berpola. Dengan demikian dapat dideskripsikan tidak terjadi masalah heteroskedastisitas.

\section{Regresi Linier Berganda}

Berdasarkan pengolahan data, dapat diketahui model persamaan regresi linear berganda dalam rumus (1). Nilai konstanta $(\alpha)$ yang ada dalam penelitian ini adalah 0,592 dan berdampak positif $(+)$ dapat dijelaskan bahwa brand image, customer experience bernilai sama dengan nol (0), maka besarnya customer satisfaction adalah 0,592. Nilai koefisien variabel Brand Image adalah 0,097 dan positif (+) menunjukkan variabel brand image dan customer satisfaction memiliki pengaruh yang positif. Nilai koefisien unutuk variabel customer experience adalah 0,110 dan bernilai positif yang menunjukkan bahwa customer experience dan customer satisfaction memiliki pengaruh yang positif.

$\mathrm{Y}=0,592+0,097 \mathrm{X}_{1}+0,110 \mathrm{X}_{2}$

\section{Uji Signifikansi Parsial (Uji t)}

Berdasar pada pengolahan data, dapat dijelaskan bahwa nilai t hitung X1 sebesar 3.066 dan didukung dengan memiliki nilai signifikan yang memiliki nilai lebih kecil dari 0,05 . Maka dapat dideskripsikan bahwa $\mathrm{H}_{0}$ ditolak dan $\mathrm{H}_{1}$ diterima, sehingga dapat dideskripsikan bahwa variabel brand image berpengaruh terhadap customer satisfaction. Nilai t hitung customer experience sebesar 4.976 dan disertai nilai signifikan yang memiliki nilai lebih kecil dari 0,05. Maka $\mathrm{H}_{0}$ ditolak dan $\mathrm{H}_{2}$ diterima, sehingga dapat dideskripsikan bahwa variabel customer experience berpengaruh terhadap customer satisfaction.

\section{Uji Kelayakan Model}

Berdasarkan pengolahan data dapat diketahui bahwa besarnya korelasi berganda antara Brand Image dan Customer Experience simultan terhadap customer satisfaction dengan korelasi sebesar 0,816. Nilai adjusted $\mathrm{R}^{2}$ sebesar $65,2 \%$ yang berarti variabel bebas berpengaruh terhadap variabel terikat sebesar $65,2 \%$ dan sisanya sebesar 34,8\% dipengaruhi oleh variabel lain di luar variabel yang digunakan dalam riset ini. 


\section{Karakteristik Responden}

\section{Tabel 1 \\ KARAKTERISTIK RESPONDEN}

\begin{tabular}{lcc}
\hline Karakteristik Responden & Jumlah & Presentase \\
\hline Jenis Kelamin & & \\
Laki-Laki & 19 & $38 \%$ \\
Perempuan & 31 & $62 \%$ \\
Kota & & \\
Surabaya Barat & 12 & $24 \%$ \\
Surabaya Selatan & 22 & $44 \%$ \\
Surabaya Timur & 13 & $26 \%$ \\
Surabaya Utara & 3 & $6 \%$ \\
Usia & & \\
17-25 & 50 & $100 \%$ \\
\hline \multicolumn{1}{c}{ Total } & $\mathbf{5 0}$ & $\mathbf{1 0 0 \%}$ \\
\hline
\end{tabular}

Sumber: Geraldi (2020)

Tabel 1 menunjukkan dari 50 responden, jika ditinjau berdasarkan kriteria jenis kelamin, ada 19 responden dengan presentase $38 \%$ berjenis kelamin laki-laki dan 72 responden dengan presentase $62 \%$ berjenis kelamin perempuan. Melalui penilaian responden diketahui bahwa responden dengan jenis kelamin perempuan lebih mendominasi. Berdasarkan kriteria kota, terdapat 12 responden dengan persentase $24 \%$ berdomisili di Surabaya barat, 22 responden dengan persentase $44 \%$ berdomisili di Surabaya selatan, 13 responden dengan persentase $26 \%$ berdomisili di Surabaya timur dan 3 responden dengan persentase $6 \%$ berdomisili di Surabaya Utara. Melalui data tersebut, diketahui bahwa responden yang berdomisili di Surabaya Selatan mendominasi. Berdasarkan kriteria usia terdapat 50 responden dengan presentase 100\% responden berusia 17-25 tahun. Melalui penilai responden diketahui bahwa seluruh responden berusia 17-25 tahun.

\section{Pengaruh Brand Image terhadap Satisfaction}

Nilai koefisien variabel Brand Image bernilai positif yang berarti adanya pengaruh positif dan signifikan antara brand image dan customer satisfaction penonton bioskop XXI, artinya semakin baik brand image bioskop XXI maka akan meningkatkan customer satisfaction. Konsumen merasa dengan adanya brand image yang baik akan meningkatkan kepuasannya saat menonton film di bioskop. Jadi para pelaku usaha bioskop harus memberikan brand image yang positif kepada penontonnya agar penonton merasa puas saat menonton di bioskopnya. Hasil ini membuktikan bahwa H1 dalam penelitian ini.

Dalam penelitian ini brand image diukur dengan menggunakan indikator dan strength, favorability dan uniqueness of brand association. Berdasarkan hasil jawaban responden menunjukkan pada item pernyataan "Studio bioskop XXI di Surabaya bersih" yang terdapat dalam indikator strength (kekuatan) merupakan jawaban dengan nilai mean tertinggi yang termasuk dalam kelas interval kategori sangatt setuju. Ini menunjukkan bahwa konsumen setuju dengan brand image mempengaruhi customer satisfaction penonton bioskop XXI. Dikaitkan dengan karakteristik responden, berjenis kelamin laki-laki dan berumur 17 - 25 tahun dan pada usia tersebut rata-rata mahasiswa atau pelajar. Berdasar dominasi responden tersebut, maka pengaruh brand image terhadap customer satisfaction penonton bioskop XXI dikarenakan penonton merasa studio bioskop XXI bersih. Artinya bioksop XXI selalu menjaga kebersihan studionya menjadi kekuatan utama bioskop XXI melebihi kebersihan studio bioskop pesaingnya

Dalam meningkatkan brand imagenya, selain menilai dari kekuatannya, pelanggan juga akan memberikan penilaian dari segi favorability. Hal ini didukung berdasarkan hasil jawaban responden melalui pernyataan dalam pengukuran favorability dengan hasil mean terbesar untuk item "Studio bioskop XXI di Surabaya bersih" yang berarti penonton merasa bahwa kebersihan studio memberikan 
Yohanes Geraldi Yuda Pradipta. Dampak Brand Image dan Customer Experience terhadap Customer Satisfaction (Studi Pada Penonton Bioskop XXI di Surabaya)

manfaat dan dapat meningkatkan nilai brand image bioskop XXI sehingga meningkatkan kepuasan menonton di bioskop XXI.

Dalam meningkatkan brand image, penonton juga akan menilai dari uniqueness bioskop XXI. Hal ini didukung dengan jawaban responden melalui pernyataan dalam pengukuran uniqueness dengan hasil mean terbesar untuk item "Bioskop XXI di Surabaya selalu menanyangkan Film terbaru" yang berarti penonton merasa Bioskop XXI selalu menayangkan film terbaru sebagai keunikan dari Bioskop XXI terhadap pesaingnya dan meningkatkan nilai brand image bioskop XXI sehingga meningkatkan kepuasan menonton di bioskop XXI.

Hasil penelitian ini mengimplikasikan teori di mana brand image yang baik akan meningkatkan kepuasan konsumen dan mendukung penelitian Budiyanto (2018), Setyowati, Erni \& Wiyadi (2016), dan Ehsan Malik et al., (2012) di mana dalam penelitian tersebut, brand image memberikan pengaruh yang positif terhadap customer satisfaction.

Implikasi dari penelitian ini adalah Bioskop XXI dalam rangka menjaga dan meningkatkan kepuasan pelanggannya perlu memperhatikan brand image mereka. Jika XXI dapat mempertahankan Strength of Brand Association, Favorable of Brand Association dan Uniquess of Brand Association yang meliputi suasana bioskop XXI di Surabaya nyaman untuk menonton film, bioskop XXI di Surabaya selalu menanyangkan film terbaru, audio bioskop XXI di Surabaya mendukung suasana film yang diputar dan studio bioskop XXI di Surabaya bersih maka kepuasan pelanggan saat menonton di bioskop XXI akan meningkat. Brand image XXI tersebut dapat dipertahankan dengan konsisten memutar film-film terbaru, melakukan maintenance secara rutin terhadap audio yang digunakan dalam bioskop, dan memastikan kondisi bioskop selalu bersih sebelum film dimulai.

\section{Pengaruh Customer Experience terhadap Customer Satisfaction}

Nilai koefisien untuk variabel customer experience bernilai positif yang menunjukkan bahwa Customer Experience $\left(\mathrm{X}_{2}\right)$ dan Customer Satisfaction (Y) memiliki pengaruh yang positif. Artinya semakin baik customer experience yang dialami penonton bioskop XXI maka akan meningkatkan customer satisfaction. Konsumen merasa dengan adanya customer experience, maka akan meningkatkan nilai dari sebuah bioskop. Jadi pelaku usaha bioskop harus memberikan pengalaman positif kepada penonton agar penonton merasa puas menonton di bioskop XXI. Hasil ini membuktikan bahwa $\mathrm{H} 2$ dalam penelitian ini.

Dalam penelitian ini, customer experience diukur dengan menggunakan indikator sense (indra), feel (perasaan), think (berpikir), act (tindakan), dan relate (hubungan). Hasil jawaban responden menunjukkan pada item pernyataan "Penonton senang dan nyaman menonton di bioskop XXI di Surabaya" yang terdapat dalam indikator feel (perasaan) merupakan jawaban dengan nilai mean tertinggi yang termasuk dalam kelas interval kategori setuju. Ini menunjukkan bahwa konsumen setuju dengan customer experience mempengaruhi customer satisfaction penonton bioksop XXI. Artinya penonton setuju merasa senang dan nyaman ketika menonton di bioskop XXI Surabaya.

Dikaitkan dengan karakteristik responden, berjenis kelamin laki-laki dan berumur $17-25$ tahun dan pada usia tersebut rata-rata mahasiswa atau pelajar yang suka pergi ke bioskop untuk menonton film kesukaan mereka. Berdasar dominasi responden terrsebut, maka pengaruh customer experience terhadap customer satisfaction penonton bioskop XXI dikarenakan penonton merasa menonton di bioskop XXI membuat mereka senang dan nyaman. Artinya bioskop XXI berhasil memberikan pengalaman yang menyenangkan untuk penontonnya, mengalahkan pengalaman menyenangkan yang diberikan bioskop pesaingnya.

Dalam memperoleh customer experience, selain menilai dari feel, pelanggan juga akan memberikan penilaian dari segi sense. Hal ini didukung berdasarkan hasil jawaban responden melalui pernyataan dalam pengukuran sense dengan hasil mean terbesar untuk item "Perabotan bioskop XXI bersih dan nyaman" yang berarti penonton merasa bahwa perabotan studio bioskop bersih dan nyaman serta 
dapat meningkatkan nilai customer experience bioskop XXI sehingga meningkatkan kepuasan menonton di bioskop XXI.

Faktor lain dalam memperoleh customer experience adalah think (berpikir). Hal ini ditunjukkan dengan hasil jawaban responden melalui pernyataan "Penonton mengikuti kabar terbaru dari Bioskop XXI melalui media sosial" Hal ini berarti penonton berpikiran untuk mengikuti kabar terbaru dari bioskop XXI melalui media sosial, sehingga dengan mendapat informasi terbaru akan meningkatkan kepuasan menonton di bioskop XXI.

Hasil penelitian ini mengimplikasikan teori semakin tinggi customer experience yang dialami maka akan semakin tinggi pula customer satisfaction dan mendukung penelitian Mulyono (2018) yang menyatakan bahwa customer experience berpengaruh positif terhadap customer satisfaction.

Implikasi dari penelitian ini adalah bioskop XXI harus menjaga kualitas dari faktor pembentuk experience yang akan dialami oleh penonton seperti desain ruangan yang menarik, ruangan yang bersih, pewangi yang digunakan dalam ruangan, musik yang diputar, dan media sosial yang menarik dan interaktif kepada penonton. Apabila experience yang diterima pentonon semakin tinggi, maka akan meningkatkan kepuasan penonton tersebut. Penonton akan merasa ekspektasinya terhadap faktor-faktor customer experience di atas terpenuhi sehingga merasa puas. Dengan rutin melakukan pembaruan kembali desain ruangan, menjaga kebersihan ruang tunggu dan studio, memberikan pengharum ruangan, memilih musik yang sesuai untuk diputar dan membangun sosial media yang menarik dan interaktif, maka experience yang dialami akan semakin tinggi dan kepuasan akan berbanding lurus dengan experience yang dialami tersebut.

\section{KESIMPULAN}

Berdasarkan hasil riset dapat diambil konklusi bahwa variabel brand image dan customer experience berpengaruh positif dengan customer satisfaction. Hal tersebut bisa diartikan penonton bioskop XXI di Surabaya dalam menentukan kepuasan setelah menonton memperhatikan brand image dan customer experience yang mereka dapatkan.

Penelitian ini masih memiliki keterbatasan dalam hal penyebaran angket. Cara peneliti melakukan penyebaran angket online pada grup-grup yang berisi responden penonton bioskop XXI di Surabaya dirasa kurang efisien, karena ternyata masih banyak jawaban responden masuk yang bertempat tinggal di luar Surabaya sehingga data tidak terpakai. Kemudian, kekurangan dalam penelitian ini adalah peneliti tidak memfokuskan pada satu bioskop XXI di Surabaya sebagai lokasi penelitiannya, sehingga membuat jawaban responden yang diperoleh menjadi kurang konsisten, karena ada sedikit perbedaan di setiap bioskop XXI di seluruh Surabaya, penelitian selanjutnya dapat memfokuskan lokasi penelitian ke salah satu bioskop XXI yang ada di Surabaya. Untuk penelitian selanjutnya, disarankan agar melibatkan variabel lain seperti kualitas layanan, diskon, dan kemudahan.

Beberapa saran untuk Bioskop XXI adalah mempertahankan dan meningkatkan brand image dengan cara konsisten memutar film-film terbaru, melakukan maintenance secara rutin terhadap audio yang digunakan dalam bioskop, dan memastikan kondisi bioskop selalu bersih sebelum film dimulai serta memperhatikan dan meningkatkan aspek-aspek customer experience yang akan dialami oleh penontonnya, dengan cara rutin melakukan pembaruan kembali desain ruangan, menjaga kebersihan ruang tunggu dan studio, memberikan pengharum ruangan, memilih musik yang sesuai untuk diputar, dan membangun sosial media yang menarik dan interaktif.

\section{DAFTAR PUSTAKA}

Budiyanto, A. (2018). Pengaruh Persepsi Harga, Kualitas Layanan dan Brand Image terhadap Tingkat Kepuasan Konsumen di PT. Yerry Primatama Hosindo. Jurnal Pemasaran Kompetitif, 1(3), $71-80$. 
Yohanes Geraldi Yuda Pradipta. Dampak Brand Image dan Customer Experience terhadap Customer Satisfaction (Studi Pada Penonton Bioskop XXI di Surabaya)

Chandra, S. (2014). The Impact of Customer Experience toward Customer Satisfaction and Loyalty of Ciputra World Surabaya. IBuss Management, 2(2), 1-11.

databoks.katadata.co.id. (2018). Jumlah Penonton Bioskop 2018 Ditargetkan Tembus 50 Juta. (https://databoks.katadata.co.id/datapublish/2018/12/26/jumlah-penonton-bioskop-2018ditargerkan-tembus-50-juta, diakses 9 September 2019).

Ehsan Malik, M., Mudasar Ghafoor, M., \& Kashif Iqbal, H. (2012). Impact of Brand Image, Service Quality and price on customer satisfaction in Pakistan Telecommunication sector. International Journal of Business and Social Science, 3(23), 123-129.

Engel F, J. et al. (1994). Perilaku Konsumen jilid 2. Jakarta: Binarupa Aksara.

Filmindonesia.or.id. (2017). Perkembangan Jumlah Bioskop Di Indonesia. (http://filmindonesia.or.id/article/kaleidoskop-2017-bioskop-yang-belum-ramah-bagisemuatahun-2017-bioskop-yang-belum-ramah-bagi-semua\#.XqT8AGgzbDc, diakses tanggal 2 September 2019)

Folley, J. (2006). Balance Brand: How To Balance The Stakeholder Forces That Can Make Or Break Your Business. San Fransisco: Jossey-Bass.

Kotler, P. \& G. A. (2008). Prinsip-Prinsip Pemasaran. (B. Sabran, Ed.) (Jilid I Ed). Jakarta: Erlangga.

Mantala, R. (2016). Pengaruh Customer Experience terhadap Customer Satisfaction pada Pengguna Smartphone Android (Studi pada Mahasiswa Politeknik Negeri Banjarmasin), Jurnal Wawasan Manajemen, 4(2), 153-164.

Mulyono, S. H., \& A, I. T. D. M. B. (2018). Pengaruh Customer Experience terhadap Customer Satisfaction di Tokopedia. e-Proceeding of Management, 5(2), 1843-1848.

Prastiyani, I., Paramita, P. D., \& Fathoni, A. (2016). Pengaruh Word Of Mouth, Brand Image, Service Quality Terhadap Customer Satisfaction Di SPBU 44.513.20 Campurejo Boja. Journal Of Management, 2(2), 1-20.

Rahmatul Hadi. (2017). Perancangan Bioskop di Kota Pontianak dengan Fasilitas Pendukung yang Rekreatif. Jurnal Mahasiswa Arsitektur Untan.

Setyowati, E. (2016). Pengaruh Kualitas Pelayanan, Harga, dan Citra Merek terhadap Loyalitas Pelanggan dengan Kepuasan Pelanggan sebagai Variabel Pemediasi. Jurnal Ekonomi Manajemen Sumber Daya Vol. 18, No. 2, Desember 2016, 102-112.

Sondakh, C. (2014). Loyalitas Nasabah Tabungan (Studi Pada Nasabah Taplus BNI Cabang Manado). Jurnal Riset Bisnis Dan Manajemen Vol.3 ,No.1, 19-32.

thejakartapost.com. (2014). First XXI cineplex closes after 10 years. (https://www.thejakartapost.com/news/2014/07/02/first-xxi-cineplex-closes-after-10years.html\#: :text=The\%20pioneering $\% 20$ Studio\%20XXI\%20cinema,entertaining $\% 20$ movieg oers\%20for\%2010\%20years, diakses 13 Oktober 2019)

Tjiptono, F., Arli, D., \& Rosari, T. S. D. R. (2015). Assessing brand origin recognition accuracy and its antecedents in a developing country. Journal of Promotion Management, 21(6), 631-648.

Tjiptono. (2001). Manajemen Pemasaran dan Analisa Perilaku Konsumen. Yogyakarta: BPFE. 
Venkat, R. (2007). Impact of Customer Experience on Satisfaction, Brand Image and Loyalty: A Study In A Business-To-Business Context. ASAC, 101-114. 